\title{
Immersion and Motivation to Become Teachers: A Comparative Study
}

\author{
Ruth Ming Har Wong \\ Department of English Language Education, The Education University of Hong Kong, Hong Kong SAR, China
}

\begin{abstract}
This study aims to investigate and compare the relationship between immersion and motivation in two different groups of student teachers who enrolled in an immersion programme. With a group of student teachers whose social and cultural backgrounds are different - one group is from Mainland China and one is from Hong Kong - though they both are of Chinese ethnicity and speak the same Chinese variety, the reasons behind their studying a postgraduate programme and going on an immersion can be different. The method of data collection adopted for this study was a qualitative paradigm. In-depth interviews, both pre- and postimmersion, were conducted. Participants were also encouraged to send e-mails to the researcher during immersion that reflected on their experience. Results show that Mainland participants were motivated by desires to enhance their pedagogical knowledge in EFL teaching in order to satisfy implementation constraints in their homeland. In contrast, Hong Kong participants were primarily interested in improving their language proficiency in order to satisfy the mandatory language assessment required for graduation. Both groups, however, saw cultural enrichment as their secondary reason for undertaking immersion, in that it allowed them to better understand the culture behind the language and thus become better English teachers.
\end{abstract}

Index Terms - motivation, immersion, language acquisition, teaching pedagogy

\section{INTRODUCTION}

The social and educational environment of HK and China are different. HK had been a British colony until 1997 where English and Chinese are both the de jure official language in HK though Cantonese is de facto official language. HK enjoys a high degree of freedom guaranteed by the Basic Law. Its education system roughly follows the British system. 'Biliterate (Chinese and English) and trilingual (Cantonese, Putonghua and English)' proficiency is emphasised. English is a compulsory subject which all students must take starting from kindergartens. Task-based teaching and communicative approach are encouraged in EFL classrooms. As for China, English is taught as a foreign language and different regions and cities may start teaching English at different school levels. The common teaching method adopted in China is grammar-translation approach. With the diverse backgrounds of the participants but going on the same immersion programme, student teachers may have different motivation orientation hence affect the learning outcomes of the immersion programme.

In this study, there are two groups of culturally diverse Chinese EFL student teachers. The two groups of participants have their reasons to study for a PGDE - a postgraduate diploma in English Language education which provides graduates with a Qualified Teacher Status (QTS) if they can pass the Language Proficiency Assessment for Teachers (LPAT). With the LPAT and a certificate in PGDE (English), graduates will be able to work as a qualified English teacher in HK. For the group of HK participants, all applied PGDE with a non-language related bachelor degree and would like to change their profession to English teaching; whilst the Mainland Chinese participants would like to have an 'overseas learning experience' other than their local degree and teaching experiences. They chose Hong Kong because of the wide use of English in HK, the city's proximity to the mainland, relatively cheap tuition fee compared to Australia, the UK and the US, and status as a free city, are other attractive factors.

One component of the current PGDE programme in this study is that all participants will need to go on an overseas immersion programme in an English-speaking country in addition to the taught modules and teaching practicum. In the past, the main purpose of an overseas immersion programme is to foster bilingualism in order to develop learners' second language proficiency and communicative competency. In addition to language enhancement, take Canada as an example, educators and parents believed that a French immersion programme would enable their students and children to appreciate the French-speaking Canadian culture as well as their own.

However, what is the participant motivation to go on an immersion programme? What would they like to achieve through immersion? Will an overseas immersion programme meet the motivation pattern of the group of postgraduate degree students? Additionally, will the same programme meet the motivation and expectations of the same group of students whom came from different cultural backgrounds? This paper intends to answer the above questions.

\section{LITERATURE REVIEW}

\section{A. Motivation}


What is motivation? The term motivation is derived from the Latin movere (to move). The idea of motivation is something that gets people going and keeps people moving. Motivation is in fact a complicated concept which can be affected by multiple interrelated dimensions of factors in determining a person's behaviour. Littlewood (1996) expressed the complexity of motivation, which includes many components like the individual's drive, need for achievement and success, curiosity, desire for stimulation and new experience. Dornyei (2001) pointed out the inherent natures of motivation in L2 research precisely that it is abstract, not directly observable, a multidimensional construct and inconstant. Dornyei (2001) described the meaning of motivation in the following terms, it "concerns the direction and magnitude of human behaviour, that is: the choice of a particular action, the persistence with it, the effort extended on it" and defined motivation as "the dynamically changing cumulative arousal in a person that initiates, directs, coordinates, amplifies, terminates, and evaluates the cognitive and motor processes whereby initial wishes and desires are selected, prioritized, operationalised and acted out" (Dorynei, 2001, p.9).

\section{B. Motivation Theories and Approaches}

In the past few decades, motivation researches appear to be in an exhilarating state of flux. According to Weiner (1992), motivation theories can be categorized into three main approaches: mechanistic approach, attribution approach and expectancy-value approach. The most prominent theories of mechanistic approach are Freud's (1926) psychoanalytic theory and Hull's drive theory. Freud believed human behaviour is driven by instinctual desires (cited in Weiner, 1992, p.28-29). Hull's drive theory (1943) believed motivation is determined by drive, habit and incentive and it is affected by frustration, anxiety, conflict and despair. However, both Freud and Hull's theories have little relation to the actual classroom setting as they both only focus on biological needs and have separated the close relationship between motivation and learning.

Attribution theory, in psychology, indicates how a person explains the causes of behaviour and events. Heider (1958) indicated that perceivers attribute the sensory data to the underlying causes in the world, and later extended this idea to attributions about people - the core processes which manifest people in their overt behaviour can be attributed to the motives, intentions and sentiments. There are two types of attributions: external and internal attribution. External attribution refers to interpreting a person's behavior caused by the situation that the person is in. Internal attribution refers to internal factors like ability, personality, mood, efforts, attitudes, or disposition which caused the given behavior. With this concept, in the context of immersion, the external attribution is that the two groups of participants are to go on an immersion programme which they may see it differently because of different internal attributions hence produce different behaviours engaging in the immersion accordingly.

The third approach is expectancy-value approach and the most classic one is Atkinson's achievement motivation theory (Atkinson, 1966). Atkinson believed human's motivational behaviours are determined by their goals and by their subjective value. He believed individuals usually maximise their personal pursuits by selecting those activities which are likely to meet their high-valued goals. His theory focuses on two main factors: expectancy of success and value, the greater likelihood the learner perceives goal-attainment and value of a specific task, the higher degree his/her motivation will be. Apart from Atkinson (1966), several theories later proposed by Rotter (1982), Locke and Lathan (1990), and Eccles and Wigfield (1995) are applicable to the research context of the present study and therefore important to be included in this study to examine student motivation to go on immersion programme.

Rotter (1982)'s social learning theory is useful to the present study as he suggested behaviour potential is determined by the expectancy of goal attainment and the value of goal or reinforcement. Locke and Lathan (1990) later developed goal setting theory which is similar to expectancy-value theory in the sense that individual believe they can achieve the goal (expectancy) and the goal is important for them (value). Task value model proposed by Eccles and Wigfield (1995) also suggested attainment value refers to personal importance of achieving the task successful while cost refers to negative value components like effort and time and other emotional costs like fear of failure and anxiety.

\section{External and Internal Attributions of Motivation}

Gardner \& Tremblay (1995) describes two distinct perspectives about motivation. The first is motivation as an element of an internal attribute. The second is motivation as an external attribute, i.e. motivation can be created by external force or reward. A hybrid perspective is that motivation can be an internal attribute and, at the same time, the result of an external force (Gardner \& Tremblay, 1995). In the socio-educational model, motivation has most frequently been characterised into two orientations (Gardner, 1985). They are intrinsic and extrinsic motivational orientation. Intrinsic orientation refers to reasons for L2 learning that are derived from one's inherent pleasure and interest in the activity; the activity is undertaken because of the spontaneous satisfaction that is associated with it. Extrinsic orientations refer to reasons that are instrumental not from the inherent interest in the activity. Gardner \& Tremblay (1995) however argued that motivation must be a characteristic of the individual and that it cannot be created out of nothing by an external force. An external force can arouse motivation, as when a teacher attempts to motivate students. The potential to be motivated must already exist and be a property of the student in order for a particular pedagogical technique to be effective. Their theory brought significant influence to the development of motivation theories and approaches in the following decades and possibly generations to come. In the context of Chinese and Hong Kong students, extrinsic and intrinsic motivational constructs are appropriate to have this group of students be tested in order to evaluate their motivation to go on an immersion. 


\section{Motivation and Immersion}

According to past studies, every student teacher undertook their immersion programme with different motivations and returned with different learning outcomes and experiences. The most common motivations for undertaking immersion were mainly due to an external force as suggested by Gardner (1996). They are: language proficiency improvement and second language acquisition enhancement (Isalelli, 2004; Kuntz \& Belnap, 2001; Pellengrion, 1998). The positive effects include fluency in speaking (e.g. Freed, 1995), lexical development (Clipperton, 1994), acquisition of phonology (Simoes, 1996); and strategy use (Lynch, Klee, \& Tedick, 2001; Ife, 2000). In the context of languageteacher training, however, some learners would like to gain teaching insights from the experience of immersion. For example, developing teaching methodology (Mahan \& Stachowski, 1989; McKay, Bowyer \& Kerr, 2001) - past studies found that learners were able to compare and contrast different school systems through immersion (Clement \& Outlaw, 2002) and acquire new attitudes and beliefs in teaching (Quinn et al, 1995). Vall and Tennison (1991-1992) argued that student teachers became more reflective about teaching. Meanwhile, immersion also caters to learners who would like to experience different levels of language input and cultural exposure (Barron, 2006; Diaz-Campos, 2004; Isabelli, 2004; Lafford, 2004) - the internal attribute suggested by Gardner (1996).

Based on the past studies, it is found that results have only focused on how immersion relates to a single aspect of learning outcome, i.e. language, teaching pedagogy (external forces) or culture (internal attribute), Heider's (1958) attribution approach and theories under the expectancy-value approach like that of Rotter's (1982), Eccles and Wigfield's (1995), Loacke and Lathan's (1995) and Gardner's (1996) deem applicable to explore the relationship between motivation and immersion.

With the application of the above psychological theoretical frameworks in this study, the significance of the study is multi-faceted:

1) There are several other motivation theories which are also applicable to be used in this study to examine participants' motivation to go on an immersion programme as stated above, this study will aim to explore the relationship between the results of the data and the stated motivation theories, and their inter-relationship, if any.

2) Studies on investigating the motivational attitudes of student teachers with different backgrounds towards immersion programme are scant, results of the present study will add new insights to the current field of study.

3) This study will focus on how learners of different backgrounds affect their motivations for experiencing immersion. With the results of the current study, it is hoped that the results will make contribution to the current literature on study abroad and/or teacher motivation, and shed light on designing an overseas immersion programmes for culturally diverse students.

\section{RESEARCH QUESTIONS}

For the purposes of this study, this paper aims to answer the following research questions:

1. What is the motivation for teachers of different backgrounds and origins share before they take part in immersion?

2. Have the motivations of teachers of different backgrounds and origins changed after they have taken part in immersion?

3. What are the reasons and relationships of the motivations found?

\section{METHODS}

\section{A. Design}

The researcher adopted a qualitative approach to data acquisition over an extended period of time in order to see the developmental changes in participant motivation. The main means of data collection was through two rounds of semistructured interviews, supported by e-mail correspondence between the researcher and the participants.

\section{B. Procedures}

At the beginning at the semester, the researcher sent an invitation letter by email to all EFL student teachers in a oneyear postgraduate diploma course in English teaching (PGDE) in Hong Kong. To avoid pressure, the group of PGDE students were not notified that the researcher would be one of the module lecturer. Eventually, 10 out of 25 students expressed interest in participating in this study: Mainland China $(n=5)$ and Hong Kong $(n=5)$. The PGDE course is comprised of 12 weeks of taught modules in Hong Kong, 6 weeks of immersion in Australia, then another 5 weeks of taught modules and 8 weeks of teaching practice in Hong Kong. The 6-week immersion consisted of 3 taught modules, teaching practice of 3 days per week, stays with local host families, and excursions. During the teaching practice, students were supervised by a serving teacher at the placement school. Students were required to conduct lesson observations, prepare lessons and teaching materials, and teach.

Before the immersion officially commenced, the investigator held an in-depth face-to-face group interview with the participants to prompt their expectations of immersion. This session was aimed to collect base-line data for the project (RQ1). Participants were also invited for another in-depth face-to-face group interview session after returning from 
immersion (RQ2). With the responses given by the participant, the researcher then compared and contrasted the motivational differences and similarities occurring over the immersion period (RQ3).

\section{Participants}

Before the PGDE course commenced, the researcher identified and invited 25 Hong Kong (HK) and Mainland Chinese EFL student teachers to participate in the project. Ten responded and expressed interests in taking part in the study. Table 1 shows the demographic features of the participants.

TABLE I.

PROFILE OF PARTICIPANTS

\begin{tabular}{|c|c|c|c|c|c|}
\hline Participant & Country of origin & $\begin{array}{c}\text { Country of } \\
\text { bachelor degree } \\
\text { awarded }\end{array}$ & Gender & $\begin{array}{c}\text { Years of } \\
\text { learning } \\
\text { English }\end{array}$ & $\begin{array}{c}\text { Years of } \\
\text { teaching } \\
\text { English }\end{array}$ \\
\hline 1 & HK & HK & F & 17 & 0 \\
\hline 2 & HK & HK & F & 17 & 0 \\
\hline 3 & HK & HK & F & 18 & 0 \\
\hline 4 & HK & HK & F & 17 & 0 \\
\hline 5 & HK & HK & M & 17 & 0 \\
\hline 6 & Mainland China & Mainland China & M & 10 & 3 \\
\hline 7 & Mainland China & Mainland China & F & 11 & 3 \\
\hline 8 & Mainland China & Mainland China & F & 10 & 4 \\
\hline 9 & Mainland China & Mainland China & F & 10 & 5 \\
\hline 10 & & Mainland China & F & 11 & 2 \\
\hline
\end{tabular}

All HK participants were students who graduated with non-English degrees and would like to become trained EFL teachers. As for the Mainland Chinese participants, they were all experienced EFL teachers with either English or education degrees. Because of the differing education systems in HK and China, the numbers of years of experience learning English were also different.

Participants from Mainland China are from Quangdong Province and their mother tongue is Cantonese while the first language of the HK participants is also Cantonese. None of the Mainland Chinese participants have studied in Hong Kong or been to Hong Kong before. When asked whether they planned to stay in HK for work after graduation, all HK participants expressed teaching in Hong Kong is their plan while none of the participants from Mainland China plan to stay. Their reason for coming to $\mathrm{HK}$ is purely for professional development.

\section{Data Collection}

Researchers conducted two rounds of semi-structured interviews with each group of participants (pre-immersion and post-immersion), i.e., four rounds of interviews.

The in-depth interview questions were structured in order to describe the developmental changes in motivation that drove them to immersion (see Appendix 1 for the interview questions). Similar semi-structured interview questions were used in the post-immersion interview to elicit any motivational change over immersion (see appendix 1).

To avoid miscommunication, interviews with the participants were conducted in their first language, Cantonese. All interviews were transcribed and translated from Cantonese to English for data analysis. Participants were also encouraged to send e-mails to the researchers to talk about their experiences any time during immersion, but this was not mandatory. By the end of the immersion, there were 24 e-mail correspondences received from the participants. Emails were all conveyed in English.

\section{E. Data Analysis}

The researcher adapted a form of the 'phenomenological' approach to analyse interview data, proposed by Hycner (1985), because it presents a clear process of reducing and analysing interview data.The data were analysed by the researcher in a reductive manner (Dörnyei, 2007), as Silverman (2000) recommended, to avoid either imposing prior categories of analysis or prematurely forming such categories. A progressive approach (Verschuren, 2003) was used whereby each stage of data analysis informed the subsequent stage of data collection. Through the analysis, segments of data were de-contextualised and then reconceptualised into thematic groups. The analysis of data consisted of three phases: pre-coding, coding, and theorising. In this way, changes on motivation before and after immersion emerged.

\section{RESULTS AND DisCUSSIONS}

In this study, all participants were asked in the pre-immersion interviews what they expected to learn from the immersion and tell the interviewer which reasons are the most important, less important and least important. Same questions were asked in the post-immersion interview to compare the responses. Data analysis revealed three main motivations for students to undertake immersion: language improvement, pedagogical enhancement, and cultural enrichment.

The motivation of going on an immersion can be categorized under Gardner's (1996) motivation framework. In the socio-educational model, motivation has most frequently been characterised into two orientations (Gardner, 1985). 
They are intrinsic and extrinsic motivational orientation. Based on the above results, the intrinsic motivation orientation is cultural enrichment; while language enhancement and pedagogical enhancement are the extrinsic motivation orientation. Meanwhile, Gardner (1996) also presented a hybrid perspective - that is: motivation can be an internal attribute and, at the same time, the result of an external force (Gardner, 1996) and the present study found that the most significant internal attribute to motivate the two groups of teachers are different although neither group had any motivational change throughout the whole process of immersion. Table 2 summarises the results of the study.

TABLE II.

MOTIVATION AND IMMERSION

\begin{tabular}{|c|c|c|c|c|}
\hline $\begin{array}{c}\text { Motivation for going on } \\
\text { Immersion }\end{array}$ & \multicolumn{2}{|c|}{ Mainland Chinese participants } & \multicolumn{2}{|c|}{ Hong Kong participants } \\
\cline { 2 - 5 } & Pre-immersion & Post- immersion & Pre-immersion & Post- immersion \\
\hline Language improvement & Least important & Least important & Most important & Most important \\
\hline Pedagogical enhancement & Most important & Most important & Least important & Least important \\
\hline Cultural enrichment & Less important & Less important & Less important & Less important \\
\hline
\end{tabular}

Table 2 shows that the Mainland Chinese teachers saw enhancing pedagogy as their main reason for immersion, followed by cultural enrichment and language improvement. However the main motivation for Hong Kong teachers was language improvement. Cultural enrichment was of secondary importance while pedagogical enhancement was seen as the least important. Further qualitative data below elaborates on the contrasting results. The reason for the consistency in motivation for immersion was revealed in e-mail correspondences and interviews of several respondents.

In one e-mail correspondence a Mainland participant stated,

"This is really a good experience. I saw students of different nationalities sitting in one class. The method the teacher used was also something I had never seen before. In this coming few weeks, I must try to absorb as much as I can." (CT 4, e-mail correspondence 20081214)

The above email excerpt can be explained by the goal setting theory suggested by Locke and Lathan (1990) why Mainland Chinese are motivated to enhance their pedagogy. According to the above excerpt, Mainland participant demonstrated her/his goal of experiencing and absorbing different teaching methods can be achieved (expectancy) and s/he would try 'as much as s/he can" to learn the teaching methods which is important (value) for him/her. With the goal and high value Mainland Chinese participants set for the immersion and their expectancy level on achieving the goal is high, motivation of pedagogical enhancement is therefore strong.

An e-mail from a Hong Kong participant also expressed her desire for language improvement during immersion.

"It was so difficult to fully understand what the Aussie said. Their accents are so different from ours, even to our lecturers who came from Australia. I think our lecturers had slowed down to make sure we understand them better... but now when I am here, this is not the case, I've found that I am still very far away from what I want to achieve." (HKT 5, e-mail correspondence 20081215)

This email excerpt can be explained by the task value model proposed by Eccles and Wigfield (1995). The HK participant wanted to enhance his/her language (attainment value) while the 'cost' refers to negative value components like effort and time and fear of failure and anxiety. From this excerpt, the 'cost' seemed high for the HK participant as s/he saw him/herself 'still very far away from what s/he want to achieve'. Although the Hong Kong participants believe enhancing language can be difficult, the value of enhancing language is still higher than that of pedagogical enhancement and cultural enrichment. To compare the two groups of participants' motivation by applying the theories proposed by Locke and Lathan (1990) and Eccles and Wigfield (1995) respectively, one can see that Hong Kong participants see achieving the task they set for going on an immersion is harder than that of the Mainland participants because the 'cost', in terms of anxiety is the hurdle of expectancy of success. The HK participants' view can be attributed to the need of passing the high-stake exam of LPAT and obtaining QTS which is the main objective of their enrolling the PGDE programme.

\section{A. Pedagogical Enhancement}

The difference in how the two groups viewed the importance of pedagogical enhancement were extreme, with Mainland Chinese considering it of highest importance, while Hong Kong participants considered it least. Mainland teachers considered their exposure to a different teaching context as highly important, with reasons revealed in Excerpt 1.

"We see learning how to teach as the main reason for going on immersion because I want to know how native speakers of English teach English to both EFL learners as well as the native students. I want to see how the teaching approaches are different. This is something I can't see back in Mainland China." (Excerpt 1, CT 1, pre-immersion interview, 13)

In an e-mail correspondence, a Mainland participant stated,

"Now that I am in Australia, I don't need to worry about my assignment nor work back home. I am pretty "empty" and waiting to be filled with insights... I found I am more receptive to new ideas in teaching." (CT 2, e-mail correspondence 20081211)

However, the HK group saw pedagogical enhancement as least important, as indicated by this participant: 
"I don't think seeing how teachers of different countries teach is very important because teaching English to EFL learners are very individualistic. Observing how others teach in other countries may not help my teaching in my own context." (Excerpt 2, HKT 1, pre-immersion interview, 20)

On the other hand, Mainland teachers saw their teaching in a Western context as a great asset to their professional portfolio.

"If our students know that I had taught overseas or studied overseas, they tend to give us more respect because we are different from other English teachers. That's why I see the teaching experiences during immersion as a great bonus to my teaching experience". (Excerpt 3, CT 2, preimmersion interview, 17)

Mainland participants saw developing pedagogy as their main motivation for undertaking immersion. Past studies, such as Mahan \& Stachowski (1989) and McKay, Bowyer \& Kerr (2001), also echoed the results of this study. Olson, and Jimenez-Silva (2008), found that studying abroad had a positive effect on both confidence and underlying ideological beliefs about teaching English language learners. Siegle \& McCoach (2007) also concluded that immersion will normally enhance self-efficacy.

In China, with the heavy emphasis on the public examination, most teachers teach English according to the format of the public examination which in turn makes English learning monotonous and dull. Also, language knowledge weighs heavier than language use in EFL classroom because of the use of grammar-translation approach. Students place learning grammar and vocabulary the top priority in English learning hence expect teachers to teach the way they expect them to be. Young and Wong (2009) pointed out that students were not ready to accept any new approaches beyond their cultural framework.

However, according to the present study, pedagogy was considered important by the Mainland participants The Chinese participants would like to implement innovative teaching approaches and ideas in their classrooms although they could neither change the curriculum nor the assessment. They believed that their students deserve a chance to enjoy the fun of learning English and learning English is not purely for instrumental values. Within their own classrooms and their own reach, they would like to bring in new teaching and learning approaches for students to experience the beauty of English and learning English can be of cultural and other values.

Now that the Mainland Chinese participants had experienced how English could be taught, they can reflect on how they can fine-tune and improve on what they can implement in their future teaching when they go back to China. Immersion was an opportunity for them to test their teaching hypothesis. As Vall and Tennison (1991-1992) believed, student teachers became more reflective about their assumptions and behaviours, and more active in problem-posting and experimentation of alternatives. Previous studies, like Williams and Kellecher (1987), also echoed the results. It was found that through immersion participants were able to compare and contrast different school systems, as suggested by Clement \& Outlaw (2002) and Quinn et al (1995).

Alternatively, HK teachers viewed teaching experience during immersion as less important than their local teaching experience.

"Well, I think the teaching experience I am going to have at a local school will be more important to me. To my potential employers, the teaching experience I had during immersion was only part of my studies. What they care more... also what I care more... is the local teaching experience." (Excerpt 4, HKT 3, post-immersion interview, 35)

The two groups of participants see pedagogical enhancement differently because their expected 'values' of the exposing to different teaching approaches and pedagogy are not the same. The Mainland participants see the value of enhancing pedagogical knowledge their prime objective of going on an immersion while the Hong Kong participants do not because the 'value' to their professional development is low.

\section{B. Language Improvement}

Another contrasting view emerged regarding views on language improvement, in that HK participants saw immersion as a chance to enhance their language proficiency, while the Mainland group did not.

"In the whole immersion programme, I very much look forward to the home stay experience. I want to see how I will react to a 100\% English environment. When I am in HK, I rely on Cantonese too much. That's why I didn't bother to brush up my English. When I am in an English speaking country, I know I won't have help but to speak English only. I want to see how much impact can bring to my English proficiency." (Excerpt 5, HKT 2, pre-immersion interview, 28)

Another HK participant also expressed her concern over passing the mandatory English proficiency test for Hong Kong English teachers.

"My major concern for the whole PGDE is that, I need to pass the LPATE (Language Proficiency Assessment for Teachers of English). If I can't pass it, I can't graduate. I can only graduate with my passing the exam. That's why improving my English during immersion is my major concern. I will make sure I speak English only and interact more with the local people. Even my English may not be able to significantly improved, at least I want to boost my confidence in using English. (Excerpt 6, HKT5, pre-immersion interview, 15) 
As HK participants correctly cited Hong Kong as primarily unilingual, they were particularly motivated to undergo immersion for the home stay experience as they believed it would be a major contributing factor in providing L2 learners with an authentic situation for developing both linguistic and communicative competence (Chaseling, 2001; Carlson, Burn, Useem \& Yachimowiczm, 1990; Koestler, 1986; Opper, Teichler, \& Carlson, 1990).

HK participants saw language development as the most prominent reason to go on immersion, even without teaching experience, because their biggest hurdle to graduation from the programme was passing the public examination. Immersion's positive effect on language development is based on a common assumption among educators and parents that significant contact with a host country's language will lead to higher proficiency in that language (e.g. Brecht, Davison, \& Ginsberg, 1993; Isabelli, 2004; Segalowitz \& Freed, 2004). This belief is supported by Isabelli's (2004), Coleman's (1997), and Freed, So \& Lazar's (2003) reviews of literature showing that students studying abroad attained a higher proficiency than students remaining at home. As Rotter (1982)'s social learning theory suggested that behaviour potential is determined by the expectancy of goal attainment and the value of goal or reinforcement, language enhancement is deem prominent to the group of $\mathrm{HK}$ participants because of the desire on authentic English communication and passing the LPATE. Hence much effort was emphasized by the HK participants as compared to the Mainland participants.

However, Mainland Chinese participants did not seem to worry about improving their language proficiency, as one stated,

"LPATE is not a major concern to me. My metalanguage is good enough to pass the exam. This is what we have been training all our lives back in Mainland China. Improving English is not a major concern. I just need more insights to pedagogy." (Excerpt 7, CT 2, post-immersion interview, 29)

Atkinson's achievement motivation theory (Atkinson, 1966) fully explains why the Mainland participants do not see language enhancement importantly. As Atkinson stated that human's motivational behaviours are determined by their goals and by their subjective value, Mainland participants maximise their personal pursuits by selecting those activities which are likely to meet their high-valued goals. Obviously language improvement is not perceived as high value by the Mainland participants, the motivation on language improvement is therefore relatively less strong.

\section{Cultural Enrichment}

Both Mainland China and Hong Kong participants see cultural enrichment as the second most important motivation, as the following excerpt revealed:

"I have been living in Mainland China all my life. I learn English from textbooks and TV but I have never personally experienced it. I want to be totally immersed in a western cultural environment to see what impact can bring to me as an EFL teacher." (Excerpt 8, CT4, pre immersion interview, 42)

As this excerpt shows, cultural enrichment is part of the reason for them to enhance their teaching pedagogy, both of which are closely linked.

"I wanted to live, study and socialize in a different country. I wanted to see the world beyond my own. I think living in HK only is too limited for me as an English teacher. Teaching English is not just teaching a language, we are also introducing a different kind of culture to the students. I need the exposure to a different culture to know the language better. Now I can share more with my students..." (Excerpt 9, HKT 5, post-immersion interview, 26)

Both the Mainland Chinese and Hong Kong participants named cultural enrichment as an element of professional development, but language improvement and pedagogical enhancement are still more important than cultural enrichment in the eyes of the HK and Mainland participants respectively. It revealed that both groups of participants were extrinsically motivated to undertake immersion. They saw immersion as pragmatic (Gardner \& Lambert, 1972).

Apart from both groups of participants being extrinsically motivated, they were also found to be intrinsically motivated to go on immersion. Cultural enrichment was found to be the second most important to their going on an immersion. They sought to be exposed to an authentic, native-English-speaking country in order to be immersed in the culture and thus become better teachers who understand the culture behind the target language they teach (Gardner \& Lambert, 1972).

As Mainland China is primarily mono-cultural, the Mainland participants expressed their desire to be immersed in highly-different cultures for comparison purposes. Thus enhancing their own understanding of Chinese culture, they would have deeper insights of both cultures with which to better teach their own students (Wong, 2009). As Davcheva (2002) explained, immersion programmes elevate student teachers' development of intercultural teaching, learning dispositions, and their understanding of new approaches to designing intercultural teaching materials. Wiggins, Follo and Eberly (2007) also found similar results. By understanding the culture of the target community, a positive attitude toward cultural diversity can be generated, a critical component in the preparation of teachers. Throughout the process of immersion, it is the exchange of culture with the native speakers which makes immersion meaningful to teachers. Coleman (1997), Freed (1995), Allen \& Herron (2003), and Regan (2003) affirmed that it is interaction with native speakers that drives acquisition of culture and language. To facilitate interaction with native speakers, program directors often recommend home stays, which many researchers (for review, see Schmidt-Rinehart \& Knight, 2004) view as the 
sine qua non of language study abroad, in that they serve as a potential sites for tertiary socialisation into target communities (Alfred \& Byram, 2002).

\section{Relationships between Internal and External Attributions}

Looking at the results from the study, an interesting interrelationship can be generated by examining the relevant motivational theories and approaches explain the two culturally diverse groups of participants are motivated in going on an immersion programme.

For the group of Hong Kong participants (see Figure 1), they looked at language enhancement as the main motivation source for immersion because of the need on passing the LPATE (external attribution) but their fear and anxiety of failing is high hence believing that their expectancy on not be able to achieve the set task is high. Therefore, the external attribution is influencing the internal attribution of the Hong Kong participants' motivation on immersion.

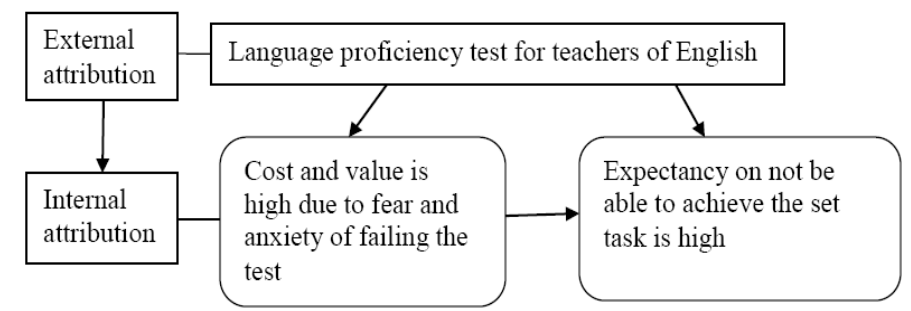

Figure 1. Language improvement and Immersion (Hong Kong participants)

For the group of Mainland Chinese participants (see Figure 2), the causal relationship is reversed. Mainland Chinese participants viewed pedagogical enhancement as a form of professional development due to their previous teacher training and the grammar-translation approach used in their school contexts (external attribution) but their fear and anxiety level of not being to experience new pedagogy is low hence believing that their expectancy on being able to develop and enhance their understanding on different teaching approaches is low. In sum, the external attribution is positively influencing the internal attribution of the Mainland Chinese participants' motivation on immersion.

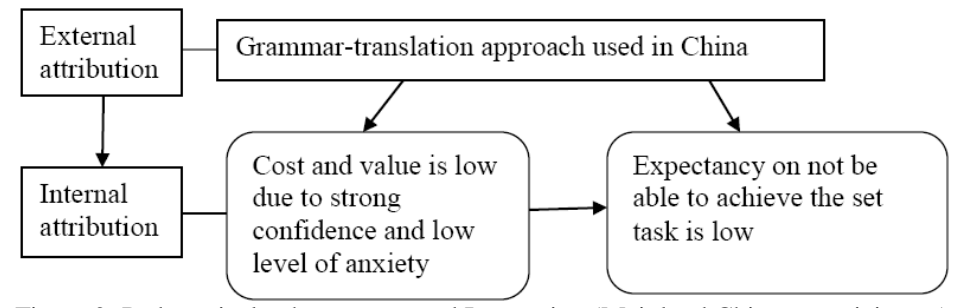

Figure 2. Pedagogical enhancement and Immersion (Mainland Chinese participants)

\section{IMPLICATIONS}

This study found that participants of two different backgrounds were both extrinsically motivated to go on immersion, but with differing orientations of extrinsic motivation. The Hong Kong group was more inclined to seek language improvement, while the Mainland group was more inclined to enhance their teaching pedagogy. If this is the case, it is wise for programme coordinators to first examine student motivation for immersion so as to adopt a more flexible approach in arranging the durations of taught modules, school attachments, home stay experiences and other culturally related matters. If some participants are more inclined to practicum, an option of a longer school-attachment scheme should be allowed.

For participants who are more concerned with language learning during their immersion programme, a local peer group can be formed to act as personal tutors to facilitate simultaneous cultural enrichment and language improvement.

Regarding the intrinsic side of motivation, care must be taken to ensure the suitability of the host family. As the country's cultural ambassadors, they will highly influence the quality of linguistic input and indeed act as the lens through which the living style and cultures (and/or subcultures) of the host country will be understood.

One point should note is that the PGDE programme should also guide students to diversify their motivations. If the Hong Kong is inclined to improve their language, then they should be called to reflect on how and what English teaching skills and approaches they can improve on. Reflecting on the differences between those they see during immersion and those they have been experiencing can be of unexpected significance to their career.

As for the Mainland Chinese participants, they should also be called to the fact that there is still much room for improvement concerning their English language skills, especially the English they use in China is likely not for daily communication but purely classroom instruction. The authentic usage of English during an immersion can facilitate and arouse their awareness to their language improvement. 
With the results found in this study, it will be worth extending the study to examine how different motivations affect what the participants gained from the immersion experience. Results will shed lights on the designing the content of the immersion programmes hence enhance the effectiveness of immersion experience to professional development.

\section{CONCLUSION}

Learners of differing backgrounds undertook immersion with different motivations, reasons which must be better understood to create better future EFL teachers. It was found that Mainland participants were motivated by desires to enhance their pedagogical knowledge in EFL teaching in order to satisfy implementation constraints in their homeland. In contrast, Hong Kong participants were primarily interested in improving their language proficiency in order to satisfy the mandatory language assessment required for graduation. Both groups, however, saw cultural enrichment as their secondary reason for undertaking immersion, in that it allowed them to better understand the culture behind the language and thus become better English teachers. Motivations for immersion can be diverse yet equally powerful in creating more reflective, innovative, superior EFL teachers.

\section{APPENDIX}

The in-depth interview questions were structured in order to describe the developmental changes in motivation that drove them to immersion. The interview questions included:

1. Are you looking forward to the immersion?

2. What do you expect to learn during immersion?

3. Of all mentioned, which one is the most important? Which one is the least important?

4. Can you explain why ___ is the most important?

5. Can you explain why ___ is the least important?

Similar semi-structured interview questions were used in the post-immersion interview to elicit any motivational change over immersion. The interview questions were:

1. Did you enjoy the immersion?

2. What did you learn from the immersion experience?

3. Which one(s) is/are the most important?

4. Which one(s) is/are the least important?

5. Why?

\section{REFERENCES}

[1] Alfred, G., \& Byram, M. (2002). Becoming an intercultural mediator: A longitudinal study of residence abroad. Journal of Multilingual and Multicultural Development, 23, 339-352.

[2] Allen, H. \& Herron, C. (2003). A mixed methodology investigation of the linguistic and affective outcomes of summer study abroad. Foreign Language Annuals, 36, 370-385.

[3] Atkinson, J. W. \& Feather, N. T. (Eds.) (1966). A Theory of Achievement Motivation. New York: Robert E. Krieger.

[4] Barron, A. (2006). Learning to say 'You' in German: The acquisition of sociolinguistic competence in a study abroad context. In M.A. DuFon and E. Churchill (Eds), Language Learners in Study Abroad Contexts (pp. 59-88). Clevedon: Multilingual Matters.

[5] Brecht, R., Davison, D. \& Ginsberg, R. (1993). Predictors of foreign language gain during study abroad. In B. Freed (Ed) Second Language Acquisition in a study abroad context (pp. 37-66), Amsterdam: John Benjamins.

[6] Carlson, J. S., Burn, B. B., Useem, J., \& Yachimowicz, D. (1990). Study aboard: The experience of American undergraduates. New York: Greenwood Press.

[7] Chaseling, M. (2001). Homestay-A home away from home. In P. Bodycott \& V. Crew (Eds.), Language and cultural immersion: Perspectives on short term study and residence abroad, (pp. 113-122). Hong Kong: Hong Kong Institute of Education.

[8] Clement, M. C. \& Outlaw, M. E. (2002). Student teaching abroad: Learning about teaching, culture, and self. Kappa Delta Pi Record, Summer, 180-183.

[9] Clipperton, R. (1994). Explicit vocabulary instruction in French immersion. Canadian Modern Language Review, 50.4, 736749 .

[10] Coleman, J. (1997). Residence abroad within language study: Language Teaching, 30.1, 1-20.

[11] Davcheva, L. (2002). Learning to be intercultural. In G. Alfred, M. Byram, \& M. Fleming (Eds), Intercultural Experience and Education. Clevedon: Multilingual Matters Ltd.

[12] Diaz-Campos, M. (2004). Context of learning in the acquisition of Spanish second language phonology, Studies in Second Language Acquisition, 26.2, 249-273.

[13] Dörnyei, Z. (2007). Research Methods in Applied Linguistics. Oxford: Oxford University Press.

[14] Dornyei, Z. \& Schmidt, R. (2001). Motivation and Second Language Acquisition. Honolulu: University of Hawaii Press.

[15] Eccles, J. \& Wigfield, A. (1995). In the Mind of the Actor: The structure of adolescents' achievement task values and expectancy-related beliefs. Personality and Social Psychology Bulletin, 21.3, 215-225.

[16] Freed, B., So, S., \& Lazar, N. (2003). Language learning abroad: How do gains in written fluency compare with gains in oral fluency in French as a second language? ADFL Bulletin, 34.3, 34-40. 
[17] Freed, B.F. (1995). What makes us think that students who study abroad become fluent? In B.F. Freed (Ed) Second Language Acquisition in a Study Abroad Context, (pp.123-148). Amsterdam: Benjamins.

[18] Freud, S. (1926). Psycho-analysis. S.E., 20, 263-270.

[19] Gardner, R. C. \& Lambert, W. (1972). Attitudes and Motivation in Second Language Learning. Rowley, Mass.: Newbury House.

[20] Gardner, R. C. \& Tremblay, P. F. (1995). On motivation: measurement and conceptual considerations. Modern Language Journal, 78, $524-27$.

[21] Hull, C. L. (1943). Principles of Behaviour. New York: Appletou-Centry Crofts.

[22] Heider, F. (1958). The Psychology of Interpersonal Relations. New York: Wiley.

[23] Hycner, R. (1985). Some guidelines for the phenomenological analysis of interview data, Human Studies, 8, 279-303

[24] Ife, A. (2000). Language learning and residence abroad: How self-directed are language students? Fremdsprachen und Hochschule, 60, 42-63.

[25] Isabelli, C. (2004). Study abroad for advanced foreign language majors: Optimal duration for developing complex structures In H. Byrnes, H. Maxim (Eds.), Advanced Foreign Language Learning, A Challenge to College Programs. (pp. 114-130). Heinle, Canada.

[26] Isabelli, C. (2004). Study abroad for advanced foreign language majors: Optimal duration for developing complex structures. In H. Brynes \& H. Maxims (Eds). Advanced Foreign Language Learning: A Challenge to College Programs (pp.114-130). Boston: Heinle.

[27] Koestler, J. (1986). A profile of foreign language majors who work, study, and travel abroad. Modern Language Journal, 70 , 21-27.

[28] Kuntz, P. and Belnap, R.K. (2001). Beliefs about language learning held by teachers and their students at two Arabic programs abroad. Al-Arabiyya, 34, 91-113.

[29] Lafford, B. (2004). The effect of the context of learning on the use of communication strategies by learners of Spanish as a second language. Studies in Second Language Acquisitionm, 26, 201-225.

[30] Liu, C. \& Littlewood, W. (1996). How Do Secondary Students Perceive Their English Learning Experience? Report on a "Young Post" Readers Survey. http://www.hkta1934.org.hk/NewHorizon/abstract/1996/page140.pdf (last accessed on 20 March 2019).

[31] Locke, E. A. \& Lathan, G. P. (1990). A Theory of Goal Setting and Task Performance. Prentice Hall, Englewood Cliffs, NJ.

[32] Lynch, A., Klee, C.A., \& Tedick, D.J. (2001). Social factors and language proficiency in postsecondary Spanish immersion: Issues and implications. Hispania, 84.3, 510-524.

[33] Mahan, J. M. \& Stachowski, L. (1990). New horizons: Student teaching abroad to enrich diversity. Action in Teacher Education, 12.3, 13-21.

[34] McKay, P., Bowyer, L., \& Kerr, J. (2001). Simultaneous immersion: Promoting language learning and teaching methodology in English immersion for teacher trainees. In P. Bodycott, V. Crew, (Eds). Language and Cultural Immersion: Perspectives in short term study and residence abroad. (pp. 35-48). Hong Kong: The Hong Kong Institute of Education.

[35] Olson, K. \& Jimenez-Silva, M. (2008). The Campfire Effect: A Preliminary Analysis of Preservice Teachers' Beliefs about Teaching English Language Learners after State-Mandated Endorsement Courses. Journal of Research in Childhood Education, $22.3,246-260$.

[36] Opper, S., Teichler, U., \& Carlson, J. (1990). Impacts of Study Abroad Programmes on Students and Graduates. London: Jessica Kingsley.

[37] Pellegrino, V. A. (1998). Student perspective on language learning in a study abroad context. Frontiers, 10, 91-120.

[38] Quinn, L. F., Barr, H., Jarchow, E., Powell, R. R., \& McKay, J. W. (1995). International student teaching: New Zealand and the United States Perspectives on Schooling. Action in Teacher Education, 18.2, 18-27.

[39] Regan, V. (2003). Sociolinguistics and language learning in s study abroad context. Frontiers, 4, 61-90.

[40] Rotter, J. B. (1982). The Development and Application of Social Learning Theory. New York: Praeger.

[41] Schmidt-Rinehart, B.C., \& Knight, S.M. (2004). The homestay component of study abroad: Three perspectives. Foreign Language Annals, 37.2, 254-262.

[42] Segalowitz, N. \& Freed, B. (2004). Context, contact and cognition in oral fluency acquisition: Learning Spanish in at home and study abroad contexts. Studies in Second Language Acquisition, 26, 173-199.

[43] Siegle, D. \& McCoach, D. B. (2007). Increasing Student Mathematics Self-Efficacy through Teacher Training. Journal of Advanced Academics, 18.2, 278-312

[44] Silverman, D. (2000). Doing Qualitative Research. London: Sage.

[45] Simoes, A. (1996). Phonetics in second language acquisition: An acoustic study of fluency in adult learners of Spanish. Hispania, 76, 87-95.

[46] Vall, N. G. \& Tennison, J. M. (1991-1992). International student teaching: Stimulus for developing reflective teachers. Action in Teacher Education, 13.4, 31-36.

[47] Verschuren, P. (2003). "Case Study as a Research Strategy: Some Ambiguities and Opportunities.” International Journal of Social Research, 6.2, 121-139.

[48] Weiner, B. (1992). Human Motivation: Metaphors, theories and research. London: Sage.

[49] Wiggins, R. A., Follo, E. J. \& Eberly, M. B. (2007). The Impact of a Field Immersion Program on Pre-Service Teachers' Attitudes toward Teaching in Culturally Diverse Classrooms. Teaching and Teacher Education: An International Journal of Research and Studies, 23.5, 653-663.

[50] Williams, L., Kellecher, R. (1987). International student teaching: Linkage for change. Innovative Higher Education, 11.2, 8493.

[51] Wong, R. (2009). National Identity Change: Overseas Students Returning to Hong Kong, The Linguistics Journal, 4, 36-62.

[52] Young, K. \& Wong, R. (2009). From outside in: from inside out; student's expectations and perceptions of culturally different teaching styles. Asia EFL Journal, 40, 28-51. 
Ruth Wong is an assistant professor at Department of English Language Education, The Education University of Hong Kong. Her research areas include student learning motivation, teaching pedagogy and cultural issues related to education. She has published textbooks, professional articles and research papers in various international journals. 